\title{
Analysis of the allocative efficiency of social service entities for sustainable development
}

\author{
Ekaterina Ogorodnikova ${ }^{1, *}$, Alexander Mokronosov ${ }^{1}$, Maria Kompaniets $^{2}$, Maria \\ Khokholush $^{1}$, and Maria Selezneva ${ }^{1}$ \\ ${ }^{1}$ Ural State University of Economics, st. March 8, 62/45, 620144 Yekaterinburg, Russia \\ ${ }^{2}$ Slavonic University of the Republic of Moldova, MD-2068 Chişinău, Republic of Moldova
}

\begin{abstract}
The relevance of the study lies in the essential role of the social services sector in matters of sustainable economic development. The purpose of the article is to analyze the allocative efficiency of the activities of the social service entities. The methodology of allocative efficiency makes it possible to identify a model of the organizational and economic mechanism of the social services sphere, which implements the tasks of the most efficient use of limited resources. The research results show higher efficiency of government institutions, higher volume of services provided and lower costs per client. This feature is due to the relative mass of service and low costs for the provision of stationary premises, the use of a tender procurement system.
\end{abstract}

\section{Introduction}

At present, methodological approaches to determining the effectiveness of the organizational and economic mechanism of the social services sphere have been formed within the framework of the infrastructure-distribution methodology and are aimed at assessing the provision of the population with appropriate social infrastructure facilities. In the works carried out within the framework of the normative approach, complex indicators can be used that characterize the provision of institutions in the social services sphere, the implementation of certain standards, and budgetary provision. For example, the article by N.I. Yashina [1] provides a set of 24 indicators that allow, according to the author, to assess the final standardized indicator for assessing the effectiveness of budgetary financing of health care. The article by A. N. Ilchenko [2] presents an integral model assessing the development of socio-economic infrastructure, including indicators of the provision of certain benefits.

The second group of methods reflects the assessment of the effectiveness of the organizational and economic mechanism of the social services sector using statistical tools for processing primary data. In the work of N.M. Surnina [3] noted that the integrated monitoring system for infrastructure development is based on statistical tools in the study of analytical indicators of time series. A similar approach is presented in the work of O.Yu. Ulyanova [4], who highlighted such criteria of the model's effectiveness as "the

*Corresponding author: cmb_8@mail.ru 
timeliness of the services provision, which preserves the rhythm of production and life and the adaptability of infrastructure institutions to cultural and technological changes in the structure of demand." The group of statistical methods also includes the cluster analysis, which make it possible to differentiate territories depending on the efficiency of the functioning of the organizational and economic mechanism of the social services sphere. Various aspects of the application of this approach are considered in the works of Alter [5], Bartlett [6], Baruch and Ramalho [7].

Survey methods for assessing the effectiveness of the organizational and economic mechanism of the social services sphere are based on the methodology set out in the order of the Ministry of labor of the Russian Federation No. 995n dated 12/08/2014, which presents 52 indicators of an independent assessment of the quality of the relevant organizations activities. Summarizing the results of the application of survey methods, the authors note the overestimation of the positive characteristics of the existing organizational and economic mechanism of the social services sector: the completeness of filling out the questionnaires is satisfactory, the employees of the assessed institutions provide the respondents and interviewers with the necessary assistance, the survey results indicate sufficient satisfaction of the service recipients.

The group of methods, assuming an assessment of the economic efficiency of the existing organizational and economic mechanism of the social services sector, involves the use of investment design methodology, that is, the authors use the principles applicable to the commercial sector, which contradicts the foundations of the formation of the organizational and economic mechanism of the social services sector. For example, the work of A.V. Chisnikov [8] provides a rationale for the development of regional social infrastructure based on comparing budget expenditures and products created on the basis of investment data. In the works of V.O. Evseev and A.V. Materkin [9] there are presented models of the dependence of the volumetric indicators of the social service system on individual factors of production, however, there are no comparative algorithms to identify the most effective form of activity in the specified market.

\section{Methods}

Despite the high importance of the above approaches, the task is to form the organizational and economic mechanism of the social services sphere within the framework of the allocative efficiency methodology, within which producers will implement the task of the most efficient use of limited resources [10,11]. This requirement is due to the resource deficit in the functioning of the organizational and economic mechanism of the social services sector. To solve the problem of analysis and the subsequent formation of the organizational and economic mechanism of the social services sphere, a methodology was formed, the algorithm of which is shown in Figure 1. 


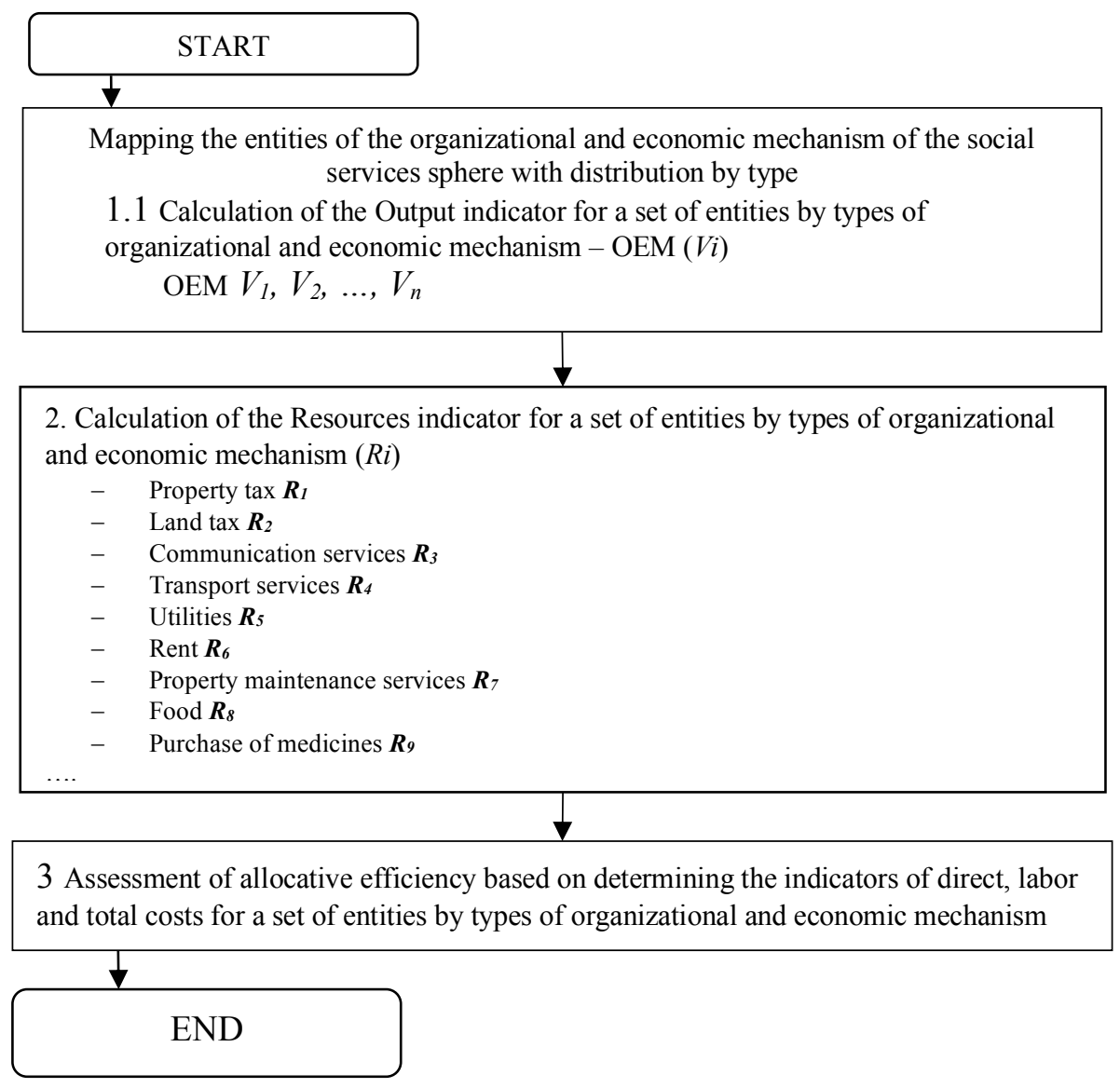

Fig. 1. Algorithm for determining the allocative efficiency of different types of organizational and economic mechanism of the social services sphere

The first stage of the methodology is the mapping of the entities of the social services sphere in the context of industry affiliation and the type of organizational and economic mechanism:

- Infrastructure and distribution OEM;

- Market OEM;

- OEM of activities of socially oriented non-profit organizations;

- Participatory OEM.

The study is carried out for the territory of the Russian Federation as a whole, while the subsequent implementation of the recommendations is carried out based on the aims of designing an organizational and economic mechanism for a specific local area. This approach will allow avoiding distortions of the assessment under the influence of territorial differentiation factors, in particular: the cost of energy resources, access to gas supply, and individual measures of institutional regulation [13]. The sources of data for organizations that are state and municipal property is the Unified portal of the budgetary system of the Russian Federation, to determine the number of services provided by organizations within the market OEM and non-profit organizations, data from the portal of the Unified State Information 
System for Social Security are used, as auxiliary sources of information we used analytical SPARK-interfax system and information from the sites of the surveyed organizations.

At the second stage of the methodology implementation, the total resources involved in the activities of entities by types of organizational and economic mechanism are determined. It is advisable to group these resources according to the following sources: financing of the fulfillment of the state task, paid services to the population and donations. As a rule, the structure of attracted resources depends on the form of ownership: organizations that are in state and municipal ownership are financed from the funds of the respective budgets, organizations of private ownership - from payments of the population, non-profit organizations - from donations.

Further, the determination of indicators of individual resources expenditure $\left(R_{1} \ldots 71\right)$ is carried out, the structure of expenditures depends on the type of organizational and economic mechanism of the social services sphere.

The results obtained make it possible to proceed to the stage of determining the allocative efficiency of a set of entities by types of organizational and economic mechanism. This approach will make it possible to determine the comparative advantages of various options for the use of resources by the entities of the organizational and economic mechanism of the social services sphere. Understanding the differences in the internal economic mechanism and external institutional regulation of various types of entities, it is possible to subsequently design a hybrid organizational and economic mechanism for the social services sphere, which most effectively uses limited resources.

\section{Results}

The provision of social services in a stationary form is carried out mainly by state and municipal organizations, at the same time, the private sector is quite developed in the Central, Northwestern and Siberian federal districts of the Russian Federation. The number of participants in this segment did not include charitable organizations, which is explained by the closed nature of information about the distribution of funds, the semi-legal nature of activities in this segment. Municipal-owned market participants include integrated social service centers with inpatient departments for pensioners and disabled people. Non-state participants, on the one hand, specialize in a certain segment of recipients, and, on the other, they dwell on a specific form of their provision: with accommodation, at home, visiting an institution.

A similar situation is observed in the provision of social services in a stationary form for orphans and children with special needs. Despite the prevalence of state institutions, organizations of a private form of ownership are presented in all federal districts, with the exception of the North Caucasus and Far East. The specifics of the activities of entities by types of organizational and economic mechanism, which are in state and municipal ownership, presupposes a comprehensive nature of service, at the same time, social services are not interchangeable for recipients. In this regard, when modeling the activities of market participants that are in state and municipal ownership, activities with and without providing accommodation are also described. Charitable organizations are not represented. The objective reason for this situation is the lack of constant funding of activities in the form of donations.

The research results are shown in Figure 2. 


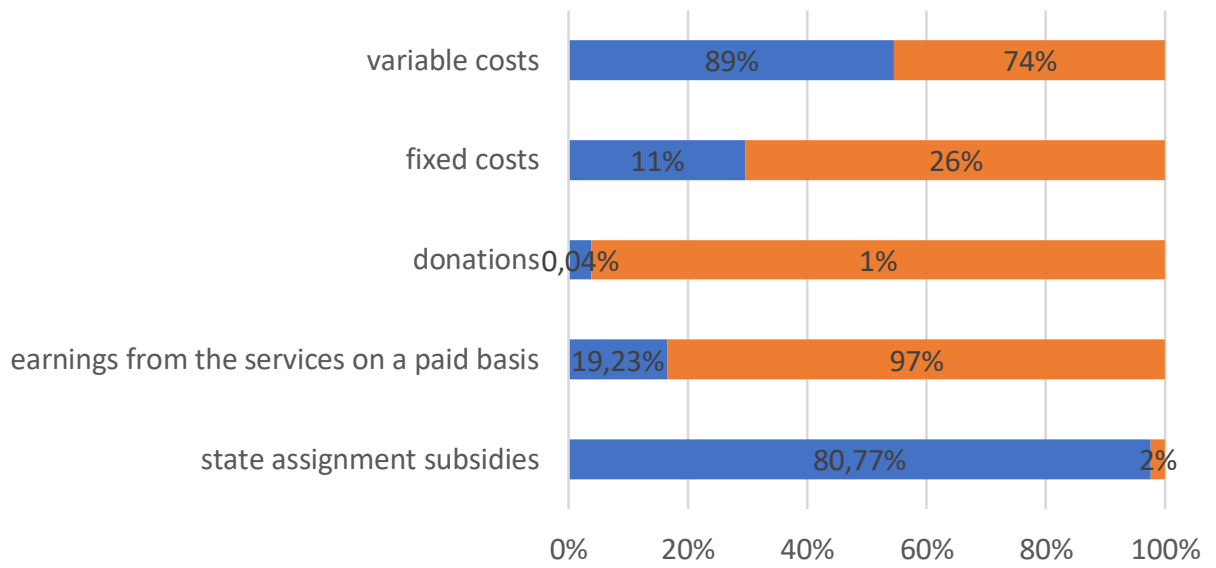

- State organizations of inpatient services for pensioners and disabled people

n Private organizations of inpatient services for pensioners and disabled people

Fig. 2. Parameters of the economic model of organizations providing residential care for the elderly and disabled, \%

Characterizing organizations that provide social services with provision of accommodation, one can note a higher concentration of beds in public institutions, on average, this value was 311 units, in private organizations of this type of activity, this value was 40 beds.

Next, let's look at the cost structure, Figure 3.

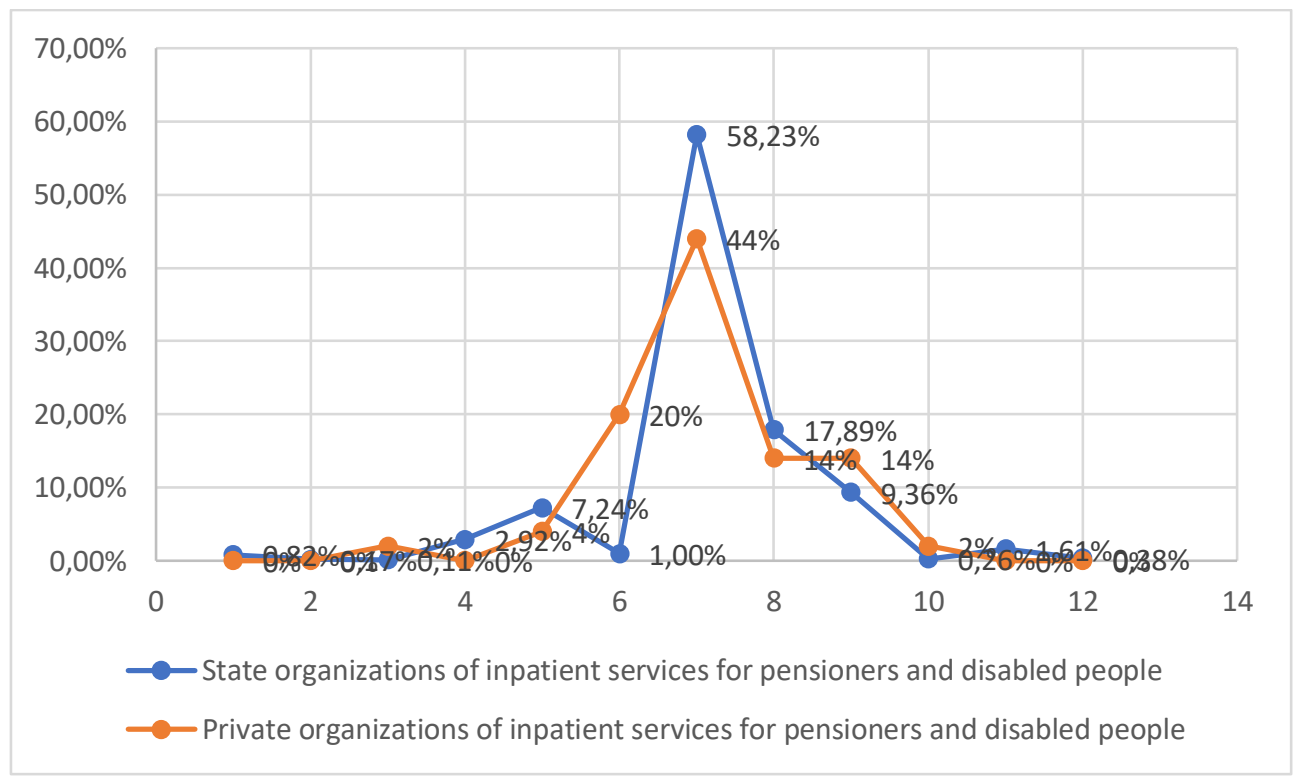

Fig. 3. The structure of expenses of organizations in the social services market, $\%$ 
Analyzing the results of comparing the cost structure of organizations operating in the field of social services in the form of government agencies and commercial organizations, it can be concluded that the structure of the costs of these organizations is fundamentally similar. Significant differences apply only to the item related to the attraction and maintenance of premises used to accommodate clients. Additionally, it should be noted that organizations of private ownership form an average profit based on performance at the level of $11-23 \%$ in relation to expenses depending on the geographical location.

\section{Conclusions}

The main result of the study is the conclusion about more effective work of organizations with state ownership in the provision of social services with the provision of accommodation. That is, the compulsory stimulation of the development of private organizations in this area of activity leads to ineffective spending of limited resources involved in the social sphere. This situation is primarily due to the recoverable profit in the course of providing socially significant activities, the share of profit, according to our estimates, is $11-23 \%$ in relation to the costs incurred. In addition to the formation of profits, private organizations do not have mechanisms to control the expenditure of resources during procurement procedures, the absence of their own stationary premises. As a result of the analysis, it can be concluded that it is necessary to enlarge private social service organizations and form a number of recommendations that limit the use of resources.

\section{References}

1. N.I. Yashina, O.V. Emel'yanova, E.S. Malysheva, N.N. Pronchatova-Rubtsova, Finance and Credit, 3 (2018)

2. A. Ilchenko, Xiang Xiao Gang, V. Stepanov, Modern high technologies, Regional application, 4 (2016)

3. N.M. Surnina, A.A. Ilyukhin, S.V. Ilyukhina, Journal of new economy, 5 (2016)

4. O. Yu. Ulyanova, S. O. Yashchenko, E. I. Chebanov, Regional economy: theory and practice, 48 (2011)

5. S.K. Alter, Social entrepreneurship: New models of sustainable social change (2006)

6. J. Bartlett, At your service: navigating the future market in health and social care Demos, London (2009)

7. Y. Baruch, N. Ramalho, Nonprofit and voluntary sector quarterly, 1 (2006)

8. A. V. Chisnikov, Improving the methodology for assessing the level of development of social infrastructure in the region: dis (2010)

9. A.V. Materikin, Economics and Law, 2 (2014)

10. T. Bovaird, Public administration, 1 (2006)

11. R.C. Feiock, H.S. Jang, Public Administration Review, 4 (2009)

12. K.P. Kearns, Public administration review, 1 (1994)

13. E.S. Ogorodnikova, A.E. Plakhin, T.V. Kochergina, P.V. Mikhailovsky, T.I.Guseva, M.V. Selezneva, Espacios, 25 (2019) 